\title{
ACL biomechanical risk factors on single-leg drop-jump: a cohort study comparing football players with and without history of lower limb injury
}

\author{
S. Daoukas ${ }^{1,2}$, N. Malliaropoulos $3,4,5,6,7$, N. Maffulli8,9,10
}

1 Third Space Sports Medicine Clinic, London, UK

2 Panhellenic Association of Sports Therapy and Rehabilitation (PASTaR), Thessaloniki, Greece

3 Sports and Exercise Medicine Clinic, Thessaloniki, Asklipiou, Greece

${ }^{4}$ National Track and Field Centre, Sports Medicine Clinic of S.E.G.A.S., Thessaloniki, Greece

${ }^{5}$ European SportsCare, London, UK

6 Sports Clinic, Rheumatology Department, Barts Health NHS Trust, London, UK

7 Centre for Sports and Exercise Medicine, Queen Mary, University of London, London, UK

${ }^{8}$ Department of Musculoskeletal Disorders, Faculty of Medicine and Surgery, University of Salerno, Via Allende, Baronissi, Salerno, Italy

9 Centre for Sports and Exercise Medicine, Barts and The London School of Medicine and Dentistry, Mile End Hospital, 275 Bancroft Road, London E1 4DG, England

10 Institute of Science and Technology in Medicine, Keele University School of Medicine, Stoke on Trent ST4 8FB, England

\section{CORRESPONDING AUTHOR:}

Nicola Maffulli

Department of

Musculoskeletal Disorders

Faculty of Medicine,

Surgery and Dentistry

University of Salerno

Via Allende

Baronissi (Salerno)

ITALY

Email: n.maffulli@qmul.ac.uk

DOI:

10.32098/mltj.01.2019.16

\begin{abstract}
SUMMARY
Background. The maximum knee valgus angle (KVA) and minimum knee flexion angle (KFA) have been identified as risk factors for non-contact anterior cruciate ligament (ACL) injury. The present study investigated whether a recent history of lower limb injury in professional male football players can affect KVA and KFA during a single-leg vertical drop-jump (SLVDJ). Methods. Twenty-one professional male football players performed a SLVDJ. The participants were divided into two groups depending on the history of a lower limb injury within the previous 12 months. Two-dimensional video analysis was used to investigate maximum KVA and minimum KFA using Kinovea software. Results. There were statistically significant differences between the injured and uninjured football players during the jump with the least ground contact time in KVA $(t=2.123, \mathrm{df}=19, \mathrm{p}$ $=0.047)$ and KFA $(\mathrm{t}=2.530, \mathrm{df}=19, \mathrm{p}=0.020)$, and in the mean KVA $(\mathrm{t}=2.359, \mathrm{df}=19, \mathrm{p}=$ $0.029)$ and KFA $(t=2.157, \mathrm{df}=19, \mathrm{p}=0.044)$. Conclusion. Football players who sustained a lower limb injury within the previous 12 months landed with increased KVA and decreased KFA at initial contact as compared to players without history of lower limb injury within the last 12 months.
\end{abstract}

\section{KEY WORDS}

anterior cruciate ligament; kinematics; lower extremity biomechanics; risk factors; vertical drop jump

\section{INTRODUCTION}

Anterior cruciate ligament (ACL) injury is common in active individuals and athletes (1). ACL injuries frequently occur in non-contact dynamic activities such as cutting or jumping (2). One of the sports with the highest risk of non-contact ACL injury is football $(3,4)$. The incidence rates in football vary from $0.15 \%$ to $3.67 \%$ per individual annually, and 0.07 to 1.08 for every 1000 sports exposures, at all ages and competition levels $(5,6)$. ACL injuries occur with motion of the knee in all three cardinal planes of motion, with decreased knee flexion or nearly extended knee joint (7), increased knee internal rotation (8) and knee valgus $(9,10)$. In vitro and in vivo studies have shed some light on understanding the biomechanics of the knee in the frontal and sagittal planes in terms of ACL loading during jumping tasks. In vivo studies have primarily used the singleleg vertical drop-jump (SLVDJ), which is considered an effective and reliable movement screening tool to assess 
non-contact ACL risk factors (11). Both in vitro and in vivo, the tensile strain of the ACL goes beyond its physiologic limit when the knee is externally rotated, flexed from $10^{\circ}$ to $30^{\circ}$, and positioned in valgus motion as athletes, whose foot is planted on the ground, internally rotate their upper body to suddenly change direction or land from a jump $(9,10)$. There is supportive evidence that sagittal and frontal plane knee-landing biomechanics alterations, particularly decreased knee valgus angle (KVA) and increased and minimum knee flexion angle (KFA) at initial contact, may contribute to reduced ACL injury rates (12).

The impact of previous lower limb injuries on ACL risk of injury in professional football players has not been extensively studied. Therefore, this cross-sectional cohort study investigates whether a previous lower limb injury can alter knee joint biomechanics during a single-leg drop-jump in professional football players. We hypothesised that football players with a lower limb injury within the previous 12 months would land with higher KVA and decreased KFA compared to their uninjured counterparts.

\section{MATERIALS AND METHODS}

Twenty-one professional football players (age: $24.24 \pm 2.9$ years; height: $1.77 \pm 0.05 \mathrm{~m}$; weight: $73.6 \pm 5.4 \mathrm{~kg}$; BMI: $23.2 \pm 0.8$ ) were divided into two groups, depending on the history of a recent injury occurred in the lower limb. A stratified sampling method was used to divide the participants of the same football club into two homogeneous subgroups, based on the occurrence of an antecedent injury (figure 1).

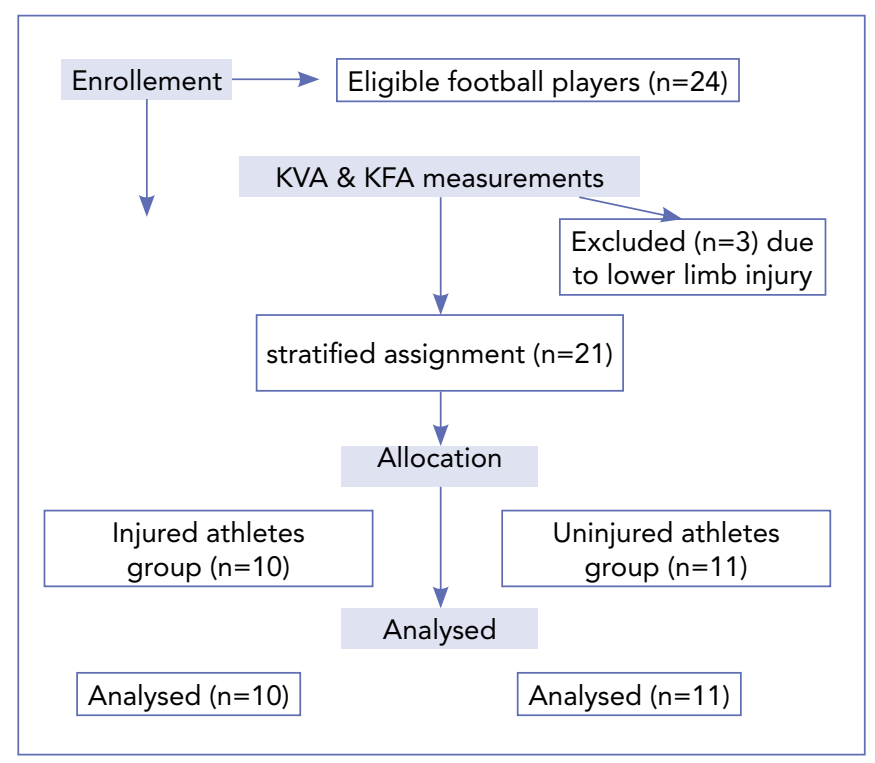

Figure 1 - Study design flowchart.
Group A consisted of 10 players who had suffered a lower limb injury within the last 12 months, and group B consisted of 11 players who had no lower limb injury during the last 12 months.

All players in Group A had sustained a soft tissue lower limb injury (table I).

Participants were included in this study if the following criteria were fulfilled: history of lower limb injury within the previous 12 months, full contact training session and official games over the last six months for group A; no history of lower limb injury within the previous 12 months, and full contact training session and official games the last six months for group B. Exclusion criteria were: injury in lower or upper limb over the previous six weeks which did not allow a player to attend training sessions and official games, and history of lower limb injury within the last 12 months which led to surgery.

Ethical approval and participants informed consent were obtained prior to conducting the investigation. The article complies with the ethical and scientific standards of Muscle, Ligaments and Tendons Journal $(13,14,15)$.

\section{Data collection}

For each participant, anthropometric data body mass $(\mathrm{kg})$, height $(\mathrm{cm})$, body mass index (BMI), as well as leg length $(\mathrm{cm})$, knee and ankle widths $(\mathrm{cm})$ were recorded prior to testing. Tracking markers were affixed to the anatomical landmarks of the dominant leg using the plug-in-gait lower-limb model (16). All markers were placed by the same investigator to ensure consistency and accurate angle measurements during the video analyses. Two-dimensional video recording data captured the drop-jump task using two digital cameras (Panasonic Video Camera V210 and V720) sampling at a rate of $50 \mathrm{~Hz}$. Both sagittal and frontal view cameras were placed $2.3 \mathrm{~m}$ away from the participant (17). Three successful trials were collected for each participant, who jumped from a 30 $\mathrm{cm}$ box (18). The jump with the least ground contact time of

Table I - Type of lower limb antecedent injury per athlete in group A.

\begin{tabular}{lll}
\hline & Frequency & Percent \\
\hline adductor strain & 1 & 10.0 \\
\hline ankle sprain & 2 & 20.0 \\
\hline gastrocnemius strain & 2 & 20.0 \\
\hline hamstring strain & 3 & 30.0 \\
\hline hip flexor strain & 2 & 20.0 \\
\hline Total & 10 & 100.0 \\
\hline
\end{tabular}


each participant from the participant's three trials was analysed (19). For each landing trial, two variables were calculated to indicate ACL risk factors: 1) maximum KVA, and 2) minimum KFA. Both variables have been identified as risk factors of non-contact ACL injury determined by a stochastic biomechanical model with a cause-and-effect relationship (20). These variables were measured at initial contact of the participants' entire foot with the floor (18). Video analysis was performed using the VirtualDubMod (21) and Kinovea softwares (22). The VirtualDubMod programme enabled us to freeze and save frames of movement during the drop landing trials. Upon appropriate frame identification and saving, the video images were uploaded into the Kinovea software to determine joint angles (figure 2 ).

\section{Statistical analysis}

All participants were allocated a code to ensure confidentiality and anonymity. The comparisons between the two groups regarding KVA and KFA were performed using the $\mathrm{t}$-test for independent samples. Spearman's correlation was used to test significant correlations between the KVA and KFA observed during the jump in which each athlete had the least ground contact time, and the mean KVA and KFA observed during the three successful trials. Statistical significance was set at $\mathrm{p}=0.05(95 \% \mathrm{CI})$ in all statistical tests. Data was analysed using SPSS (version 25.0, IBM).

\section{RESULTS}

All 21 participants successfully completed the test protocol. The t-test showed statistically significant differences in KVA between group A and group B athletes observed during the jump with the least ground contact time $(\mathrm{t}=2.123$, df $=19, \mathrm{p}=0.047)$ (table II). The average KVA was $6.20 \pm$ 5.80 degrees in group $\mathrm{A}$, and $1.73 \pm 3.71$ degrees in group $\mathrm{B}$ at initial contact. Similarly, the t-test showed statistically significant differences in KFA between group A and group $\mathrm{B}$ athletes observed during the jump with the least ground contact time $(\mathrm{t}=2.530, \mathrm{df}=19, \mathrm{p}=0.020)$ (table III). The average KFA was $35.20 \pm 7.8$ degrees in group $\mathrm{A}$, and $45 \pm$ 9.66 degrees in group B at initial contact.
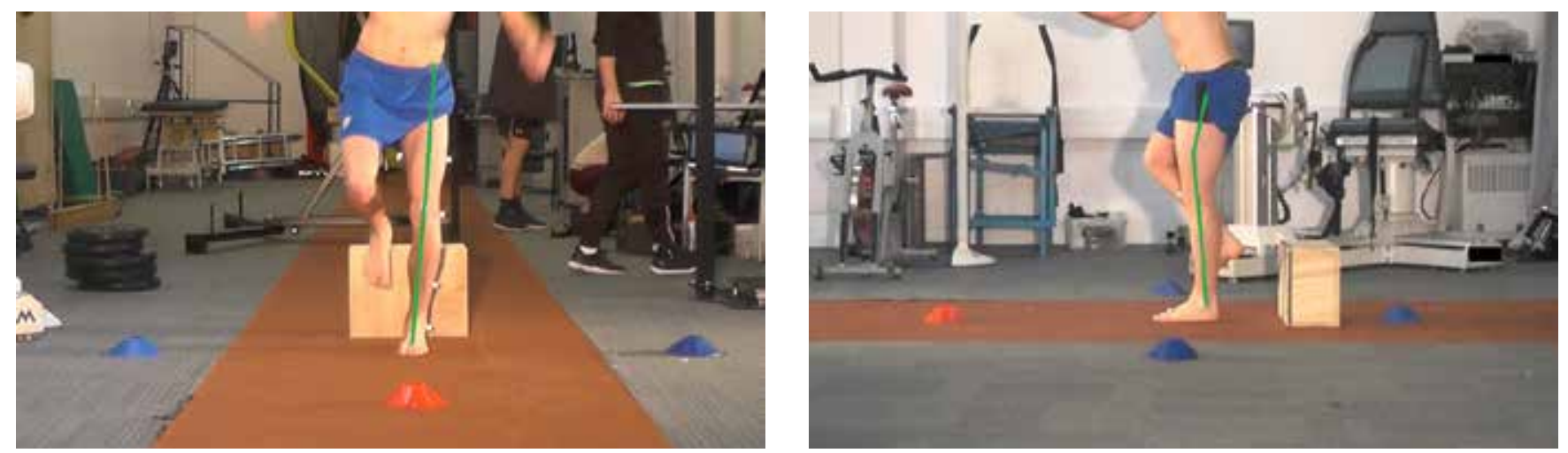

Figure 2 - Frontal and sagittal views of SLVDJ at initial contact.

Table II - Mean KVA (degrees) at the least ground contact time.

\begin{tabular}{cllccccc}
\hline & & $\mathbf{n}$ & mean $\left(^{\circ}\right)$ & std. deviation & std. error & minimum $\left(^{\circ}\right)$ & maximum $\left({ }^{\circ}\right)$ \\
\hline \multirow{3}{*}{ KVA } & group A & 10 & 6.20 & 5.808 & 1.837 & -3 & 13 \\
\cline { 2 - 8 } & group B & 11 & 1.73 & 3.717 & 1.121 & -4 & 9 \\
\cline { 2 - 8 } & Total & 21 & 3.86 & 5.228 & 1.141 & -4 & 13 \\
\hline
\end{tabular}

Table III - Mean KFA (degrees) at the least ground contact time.

\begin{tabular}{cllcccccc}
\hline & & $\mathbf{n}$ & mean $(\mathbf{o})$ & std. deviation & std. error & minimum (o) & maximum (o) \\
\hline \multirow{3}{*}{ KFA } & group A & 10 & 35.20 & 7.885 & 2.494 & 25 & 48 \\
\cline { 2 - 8 } & group B & 11 & 45.00 & 9.664 & 2.914 & 37 & 66 \\
\cline { 2 - 8 } & Total & 21 & 40.33 & 9.992 & 2.180 & 25 & 66 \\
\hline
\end{tabular}


Spearman's correlation evidenced a strong positive association between the least contact time KVA and trials' mean $\mathrm{KVA}(\mathrm{r}=895, \mathrm{p}=0.000)$. Similarly, there was a strong positive correlation between the least contact time KFA and trials' mean KFA $(r=699, \mathrm{p}=0.000)$.

\section{DISCUSSION}

The present study investigated whether a history of lower limb injury in professional male football players can affect the biomechanics of the knee joint during a single-leg dropjump (SLDJ). Those players who sustained a lower-limb injury within the last 12 months landed with increased KVA and decreased KFA at initial contact compared to their uninjured counterparts. These findings support the current literature suggesting that a history of lower extremity injury may contribute to altered knee joint biomechanics and consequently challenge the ACL tensile strength or length (23). Both KVA and KFA have been identified as risk factors for non-contact ACL injury determined by a stochastic biomechanical model with a cause-effect relationship (24).

One of the key strengths of this study was its sample size with collected lower limb injury data. We also used a two-dimensional video analysis method and the SLDJ protocol, both considered reliable and effective screening tools to assess lower limb biomechanics of ACL risk factors (25). Prior studies have focused largely on in vitro and in vivo investigations, to gain a more complete understanding of the frontal and sagittal plane knee biomechanics on ACL loading during jumping tasks $(26,27)$. There is strong supporting evidence that force placed on a nearly extended knee joint can lead to significant ACL stress (28) and cause a tear to the ACL (27). Kim et al. (29) found that the mean angle of knee flexion during SLVDJ was $12^{\circ}$ at the time of ACL rupture in 8 patients. Cochrane et al. (30) assessed 34 video records of an ACL injury in Australian football: most ACL injuries occurred as the athletes were landing or sidestepping with less than $30^{\circ}$ of knee flexion angles. Brown et al. (31) used the same technique: landing with less than $30^{\circ}$ of knee flexion increased the peak ACL length in both pre-landing and landing phases of drop vertical jumping activities. In the present study, statistically significant differences between the two groups were identified in the case of KFA observed during both the jumps, with the least ground contact time and the three trials' mean KFA: the mean KFAs in group A ranged from $36.60^{\circ}$ to $39.60^{\circ}$. These results are in contrast with prior studies investigating sagittal knee motion biomechanics on ACL risk factor. However, the minimum KFA in the present study was $22^{\circ}$, in line with previous studies. Several studies have investigated the impact of knee valgus in non-contact ACL mechanism of injury $(2,32)$. Hewett et al. (25) showed that knee valgus angles in female athletes, both initial contact and peak angles, were associated with ACL risk of injury. Koga et al. (32) conducted an analysis on the movement patterns of 10 cases of ACL injuries in female basketball and football teams. They concluded that knee valgus motion along with an almost extended knee are risk factors that cause ACL strain. In a similar study, Kim et al. (29) found that the mean angle of knee valgus was $5^{\circ}$ at the time of ACL tear in eight patients. The present study evidenced statistically significant differences between the two groups in the case of KFA observed during both the jump with the least ground contact time and the three trials' mean KFA, with the mean KVAs ranging from $4.10^{\circ}$ to $5.50^{\circ}$. The maximum KFA was $16^{\circ}$.

Both mean KFA and KVA were improved in the present study through the SLVDJ trials. The mean KVAs in the injured group were $5.50^{\circ}, 4.90^{\circ}$, and $4.10^{\circ}$ in the first, second, and third trial, respectively. The mean KFAs were $36.60^{\circ}, 36.60^{\circ}$, and $39.60^{\circ}$ in the first, second, and third trial, respectively. These results show that SLVDJ training or even warm-up can presumably decrease KVAs and increase KFAs. There is supportive evidence that sagittal and frontal plane knee-landing biomechanics alterations, particularly decreased knee valgus and increased knee flexion angles at initial contact, may contribute to a reduction in ACL injury rates $(32,33)$.

Our study has several differences when compared to prior studies which have focused on ACL risk factors. Hewett et al. (25) and Krosshaug et al. (34) measured multiple variables, including hip joint angles. Our study included only two variables which are considered as potential ACL risk factors, but the results were chosen based on previous studies. Other differences include participant characteristics. Our study group was older $(24.24 \pm 2.9$, range 19 to 30 years) and presumably as well trained as the elite adult group studied by Krosshaug et al. (34). In the present study, all participants were playing in official football games $(\mathrm{n}=$ 21); one important risk factor for ACL injury is the level of competition. The increased training loads and physical demands in professional football leagues contribute to a higher risk of ACL injury (35).

Activities that include performing a task on one leg such as single-leg landing are highly associated to ACL non-contact injuries (2). Our study highlights the importance of history of lower limb injury on biomechanical alterations of the knee joint, and consequently for non-contact ACL risk of injury. Future studies should focus on investigating potential risk factors in football-specific movement on the football pitch environment, where players are less aware of being recorded. Obviously, under laboratory condition they may demonstrate different KVA and KFA values. 


\section{LIMITATIONS}

This study has some limitations. Ground Reaction Force (GRF) is a highly accurate tool to measure both initial contact time and reaction force (36,37). We did not study GRF in the present study. Although studies have suggested that both sagittal and frontal knee motion planes contribute to ACL injury $(32,38)$, the relationship between ACL risk of injury and stiff landing was not measured. Lower limb injury data were collected; however, no further investigation was made to ascertain the effect of each type of injury on knee kinetics and kinematics during a SLDJ. The findings of our study should be used to further explore and examine the association between specific lower limb injuries and KFA and KVA in elite football players.

\section{CONCLUSION}

This is one of the few studies relating two-dimensional video analysis on KFA and KVA angles during the SLVDJ with lower limb biomechanics and non-contact ACL risk factors in professional male football players. Players who sustained a lower-limb injury within the previous 12 months landed with increased KVA and decreased KFA at initial contact compared to players without a history of lower limb within the previous 12 months. Rehabilitation and return to sport programme should focus on restoring the normal kinematics of the lower limb following soft tissue lower limb injuries in professional football players.

\section{Conflict of interest}

The authors declare that there are no personal or commercial relationships related to this study that would lead to a conflict of interest.

\section{REFERENCES}

1. Hootman JM, Albohm MJ. Anterior cruciate ligament injury prevention and primary prevention of knee osteoarthritis. J Athl Train 2012;47(5):589-590.

2. Walden M, Krosshaug T, Bjornejoe J, Andersen TE, Faul $\mathrm{O}$, Hagglund M. Three distinct mechanisms predominate in non-contact anterior cruciate ligament injuries in male professional football players: a systematic video analysis of 39 cases. Br J Sports Med 2015;49(22):1452-1460.

3. Granan LP, Bahr R, Steindal K, Furnes O, Engebretsen L. Development of a national cruciate ligament surgery registry: the Norwegian national knee ligament registry. Am J Sports Med 2008;36(2):308-315.

4. Gianotti SM, Marshall SW, Hume PA, Bunt L. Incidence of anterior cruciate ligament injury and other knee ligament injuries: a national population-based study. J Sci Med Sport 2009;12(6):622-627.

5. Prodromos CC, Han Y, Rogowski J, Joyce B, Shi K. A meta-analysis of the incidence of anterior cruciate ligament tears as a function of gender, sport, and a knee injury-reduction regimen. Arthroscopy 2007;23(12):1320-1325.

6. Moses B, Orchard J, Orchard J. Systematic review: annual incidence of ACL injury and surgery in various populations. Res Sports Med 2012; 20(3-4):157-179.

7. Quatman CE, Quatman-Yates CC, Hewett TE. A plane explanation of anterior cruciate ligament injury mechanisms: a systematic review. Sports Med 2010; 40(9):729-746.

8. McLean SG, Lipfert SW, Van Den Bogert AJ. Effect of gender and defensive opponent on the biomechanics of sidestep cutting. Med Sci Sports Exerc 2004; 36(6):1008-1016.

9. Boden BP, Sheehan FT, Torg JS, Hewett TE. Non-contact ACL injuries: Mechanisms and risk factors. J Am Acad Orthop Surg 2010; 18(9):520-527.

10. Teitz CC. Video analysis of ACL injuries. Prevention of Noncontact ACL Injuries. Am Acad Orthop Surg 2001; 4(11):93-96.

11. Redler LH, Watling JP, Dennis ER, Swart E, Ahmad CS. Reliability of a field-based drop vertical jump screening test for ACL injury risk assessment. Phys Sportsmed 2016; 44(1):46-52.

12. Chappell JD, Limpisvasti O. Effect of a neuromuscular training program on the kinetics and kinematics of jumping tasks. Am J Sports Med 2008; 36(6):1081-1086.

13. Padulo J, Oliva F, Frizziero A, Maffulli N. Muscles, Ligaments and Tendons Journal - Basic principles and recommendations in clinical and field science research: 2016 update. MLTJ 2016; 6(1):1-5.

14. Padulo J, Oliva F, Frizziero A, Maffulli N. Basic principles and recommendations in clinical and field science research: 2018 update. MLTJ 2018; 8(3):305-307.

15. Padulo J, De Giorgio A, Oliva F, Frizziero A, Maffulli N. I performed experiments and I have results. Wow, and now? MLTJ 2017; 7(3):403.

16. MuGhaffar M, Abboud R, Wang W. A new lower limb model for motion analysis and its comparison with Vicon Plug-inGait Model. Gait Posture 2012; 36(1):76.

17. Taylor JB, Ford KR, Nguyen AD, Shultz SJ. Biomechanical comparison of single-leg and double-leg jump landings in the sagittal and frontal plane. Orthop J Sports Med 2016; 4(6):2325967116655158.

18. Dingenen B, Malfait B, Nijs S, et al. Can two-dimensional video analysis during single-leg drop vertical jumps help identify non-contact knee injury risk? A one-year prospective study. Clic Biomech 2015; 30(8):781-787.

19. Wang L. The lower extremity biomechanics of single- and double-leg stop-jump in female basketball players with dynamic knee valgus alignment. J Phys Fitness Sports Med 2013; 2(4):501-508.

20. Lin CF, Liu H, Gros MT, Weinhold P, Garrett WE, Yu B. Biomechanical risk factors of non-contact ACL injuries: a stochastic biomechanical modelling study. J Sports Health Sci 2012; 1(1):36-42.

21. Braun HJ, Shultz R, Malone M, Leatherwood WE, Silder A, Dragoo JL. Differences in ACL biomechanical risk factors 
between field hockey and lacrosse female athletes. Knee Surg Sports Traumatol Arthroscop 2015; 23(4):1065-1070.

22. Damsted C, Nielsen RO, Larsen LH. Reliability of videobased quantification of the knee and hip angle at foot strike during running. Int J Sports Phys Ther 2015; 10(2):147-154.

23. Butler DL, Guan Y, Kay MD, Cummings JF, Feder SM, Levy MS. Location-dependent variations in the material properties of the anterior cruciate ligament. J Biomech 1992; 25(5):511-518.

24. Voleti PB, Tjoumakaris FP, Rotmil G, Freedman KB. Fifty most-cited articles in anterior cruciate ligament research. Orthopedics 2015; 38(4):297-304.

25. Hewett TE, Myer GD, Ford KR, et al. Biomechanical measures of neuromuscular control and valgus loading of the knee predict anterior cruciate ligament injury risk in female athletes: a prospective study. Am J Sports Med 2005; 33(4):492-501.

26. Withrow TJ, Huston LJ, Wojtys EM, Ashton-Miller JA. The relationship between quadriceps muscle force, knee flexion, and anterior cruciate ligament strain in an in vitro simulated jump landing. Am J Sports Med 2006; 34(2):269-274.

27. DeMorat G, Weinhold P, Blackburn T, Chudik S, Garrett W. Aggressive quadriceps loading can induce non-contact anterior cruciate ligament injury. Am J Sports Med 2004; 32(2):477-483.

28. Beynnon BD, Fleming BC. Anterior cruciate ligament strain in-vivo: a review of previous work. J Biomech 1998; 31(6):519-525.

29. Kim SY, Spritzer CE, Utturkar GM, Toth AP, Garrett WE, DeFrate LE. Knee kinematics during non-contact ACL injury as determined from location of bone bruises. Orthopaedic Research Society 2014. Annual Meeting; March 17, 2014. New Orleans, LA, USA.
30. Cochrane JL, Lloyd DG, Buttfield A, Seward H, McGivern J. Characteristics of anterior cruciate ligament injuries in Australian football. J Sci Med Sport 2007; 10(2):96-104.

31. Brown DW, Taylor KA, Utturkar GM, et al. Modification of in vivo ACL strain patterns during jump landing through verbal instruction. Orthopaedic Research Society 2012. Annual Meeting; February 5, 2012. San Francisco, CA, USA.

32. Koga H, Nakamae A, Shima Y, et al. Mechanisms for noncontact anterior cruciate ligament injuries: knee joint kinematics in 10 injury situations from female team handball and basketball. Am J Sports Med 2010; 38(11):2218-2225.

33. Kristianslund E, Krosshaug T. Comparison of drop jumps and sport-specific sidestep cutting: implications for anterior cruciate ligament injury risk screening. Am J Sports Med 2013; 41(3):684-688.

34. Krosshaug T, Steffen K, KristianslundE, et al. The vertical drop jump is a poor screening test for ACL injuries in female elite soccer and handball players: a prospective cohort study of 710 athletes. Am J Sports Med 2016; 44(4):874-883.

35. Leppanen M, Pasanen K, Kujala UM, et al. Stiff landings are associated with increased ACL injury risk in young female basketball and floorball players. Am J Sports Med 2016; 45(2):386-393.

36. Laughlin WA, Weinhandl JT, Kernozek TW, Cobb SC, Keenan KG, O'Connor KM. The effects of single-leg landing technique on ACL loading. J Biomech 2011; 44(10):1845-1851.

37. Myers CA, Torry MR, Peterson DS, et al. Measurements of tibiofemoral kinematics during soft and stiff drop landings using biplane fluoroscopy. Am J Sports Med 2011; 39(8):1714-1722.

38. Meyer EG, Haut RC. Anterior cruciate ligament injury induced by internal tibial torsion or tibiofemoral compression. J Biomech 2008; 41(16):3377-3383. 